This manuscript is a preprint and has been submitted for peer review to PLOS ONE. If accepted, the final version of this manuscript will be available via the 'Peer-reviewed Publication DOI' link on the right-hand side of this webpage. Please do not hesitate to contact Paul Stoy at the email provided on the title page of the manuscript if any questions arise. 


\section{The spatial dynamics of wheat yield and protein content at the field scale}

2 Paul C. Stoy ${ }^{1,2, *}$, Anam Khan ${ }^{2}$, Aaron Wipf $^{3}$, Nick Silverman $^{4}$, Scott Powell ${ }^{3}$

$3 \quad{ }^{1}$ Department of Biological Systems Engineering, University of Wisconsin - Madison

$4 \quad{ }^{2}$ Nelson Institute for Environmental Studies, University of Wisconsin - Madison

$5{ }^{3}$ Department of Land Resources and Environmental Sciences, Montana State University

$6 \quad{ }^{4}$ Adaptive Hydrology, LLC

$8 \quad{ }^{*}$ Corresponding author: pcstoy@wisc.edu

\section{Abstract}

11 Wheat is a staple crop that is critical for feeding a hungry and growing planet, but its nutritive value has

12 declined as global temperatures have warmed. The price offered to producers depends not only on yield but

13 also grain protein content (GPC), which are often negatively related at the field scale but can positively 14 covary depending in part on management strategies, emphasizing the need to predict their variability within 15 individual fields. We measured yield and GPC in a winter wheat field in Sun River, Montana, USA and 16 tested the ability of normalized difference vegetation index (NDVI) measurements from an unpiloted aerial 17 vehicle (UAV) on spatial scales of $\sim 10 \mathrm{~cm}$ and from Landsat on spatial scales of $30 \mathrm{~m}$ to predict them.

18 Landsat observations were poorly related to wheat measurements. A multiple linear model using 19 information from four (three) UAV flyovers was selected as the most parsimonious and predicted $26 \%$ $20(40 \%)$ of the variability in wheat yield (GPC). We sought to understand the optimal spatial scale for 21 interpreting UAV observations given that the $\sim 10 \mathrm{~cm}$ pixels yielded more than 12 million measurements 22 at far finer resolution than the $12 \mathrm{~m}$ scale of the harvester. The variance in NDVI observations was 23 'averaged out' at larger pixel sizes but only $\sim 20 \%$ of the total variance was averaged out at the spatial scale 24 of the harvester on some measurement dates. Spatial averaging to the scale of the harvester also made little 25 difference in the total information content of NDVI fit using Beta distributions as quantified using the 
26 Kullback-Leibler divergence. Radially-averaged power spectra of UAV-measured NDVI revealed

27 relatively steep power law relationships with exponentially less variance at finer spatial scales. Results

28 suggest that larger pixels can reasonably capture the information content of within-field NDVI, but the 30

$29 \mathrm{~m}$ Landsat scale is too coarse to describe some of the key features of the field, which are consistent with

30 topography, historic management practices, and edaphic variability. Future research should seek to

31 determine an 'optimum' spatial scale for NDVI observations that minimizes effort (and therefore cost)

32 while maintaining the ability of producers to make management decisions that positively impact yield and

33 GPC.

\section{1. Introduction}

36 Crop yields are often quite variable within individual fields due to differences in soil fertility and 37 topography, weediness, and management efforts, but also for reasons that are not entirely clear [1]. Canopy 38 spectral reflectance indices like the normalized difference vegetation index (NDVI) are useful for 39 estimating crop yield at multiple scales in space [2-4] because the absorption and reflectance of red and 40 near infrared wavelengths is a good proxy for leaf area, which in turn is a good proxy for growth [5] and 41 yield [6]. Following this notion, the yields of many different crops have been estimated using NDVI and 42 related vegetation indices using aerial and satellite-based platforms [7-9].

43 Other crop attributes also determine price, like grain protein content (GPC) for the case of wheat

44 (Triticum aestivum L.) [10,11]. Understanding GPC is critical not only for agricultural management [12]

45 but also the global food system as it is predicted to decrease in a changing climate [13]. Wheat yield and 46 GPC are often inversely related within a field [14-16] because water stress during grain filling increases

47 GPC but decreases yield [17]. Despite this, yield and GPC can be positively related depending on edaphic 48 properties and management interventions [16,18], with great advantage to producers. Field-scale 49 management can therefore be improved by understanding relationships between NDVI, yield, and GPC.

50 The spatial variability of GPC has been successfully estimated from NDVI and other vegetation 51 indices using different remote sensing platforms [19-23], especially during latter stages of crop 
52 development, namely anthesis [24,25]. Wheat yield is often more strongly related to vegetation indices that

53 are integrated across the growing-season to capture the full period of canopy development and thereby crop

54 carbon uptake [26-28]. As with all remote sensing products, there is a tradeoff between frequent

55 measurements and spatial resolution that needs to be understood when designing observation systems.

56 Satellite platforms offer frequent observations at scales of tens of meters to kilometers, which may be

57 insufficient to capture spatial variability. Unpiloted aerial systems technologies and portable

58 spectroradiometers [29] can collect observations at spatial scales on the order of centimeters or less [30]

59 but usually make measurements rather infrequently, depending on effort, which adds cost. Wheat yield and

60 GPC can even be estimated using consumer-grade cameras [31] that can be mounted as 'phenocams' to

61 take repeat measurements at frequent intervals at fine spatial scales [32]. With these emerging technologies

62 and opportunities, an important question remains: in a data-rich world, what observations are necessary for

63 a concise description of within-field variability of wheat yield and GPC? We argue that the answer lies in

64 understanding the patterns of spatial variability of yield and GPC within wheat fields.

65 Here, we investigate the relationships between wheat yield and GPC measured by a harvester,

66 NDVI observations from an unpiloted aerial vehicle (UAV) at the scale of approximately $12.5 \mathrm{~cm}$, and

67 NDVI observations at $30 \mathrm{~m}$ from Landsat. We ask if the spatial scale of Landsat is sufficient to characterize

68 field-scale variability in wheat yield and GPC and, hypothesizing that it is not, seek to understand which

69 UAV-based observations create the best fit with both yield and GPC observations. We then quantify the

70 consequences of spatial averaging on NDVI statistics and information loss to quantify the compromises

71 that one makes by observing at coarser spatial resolution. We discuss our findings in the context of field-

72 scale management and ways to efficiently use spatial data to improve wheat yield and GPC.

73

\section{2. Methods}

\section{$75 \quad 2.1$ Study Site}

76 Measurements were made in an agricultural field located south of Sun River, Montana, USA (Figure 1)

77 [33]. Mean annual temperature over the past 30 years at the Great Falls International Airport located $25 \mathrm{~km}$ 
78 due east of the study site is $7.0^{\circ} \mathrm{C}$ and mean annual precipitation is $375 \mathrm{~mm}$. The study area is $420 \mathrm{~m}$ in the

79 east-west direction and $570 \mathrm{~m}$ in the north-south direction with rows oriented north-south. Brawl CL Plus

80 hard red winter wheat [34] was planted in 2015 and harvested in 2016 following a year of summer fallow

81 in 2015, winter wheat harvested in 2014, a combination of pea (Pisum sativum), lentil (Lens culinaris), and

82 mustard (Brassica hirta) harvested in 2013, and summer fallow in 2012.

83

\section{$84 \quad 2.2$ NDVI acquisition and analysis}

85 We acquired multi-spectral imagery on May 19, June 8, July 1, and July 20, 2016 between 900 and 1400

86 local standard time to minimize sun angle effects, with most flights occurring within an hour of 1000.

87 Observations from the different dates are subsequently abbreviated $\mathrm{NDVI}_{\text {date. }}$. We first established eight

88 permanent ground control points using a R8-3 base station and a R8-4 multi-constellation GNSS receiver

89 (Trimble, Sunnyvale, CA, USA), and achieved 1.5 to $1.8 \mathrm{~cm}$ precision at a $95 \%$ confidence interval in both

90 the horizontal and vertical directions. Green $(550 \mathrm{~nm})$, red $(660 \mathrm{~nm})$, red edge $(735 \mathrm{~nm})$ and NIR $(790 \mathrm{~nm})$

91 bands were measured using a senseFly multiSPEC 4C camera mounted on an eBee drone (senseFly Ltd.,

92 Cheseaux-Lausanne, Switzerland) with integrated inertial measurement unit, global positioning system

93 (GPS), and autopilot. The multiSPEC 4C camera contains an integrated upward-facing irradiance sensor,

94 which was calibrated prior to each flight with an Airinov MultiSPEC 4C calibration target. This allowed us

95 to convert spectral radiance to reflectance and compare NDVI among measurement dates. SenseFly

96 eMotion 2 software was used for flight planning, execution, and preliminary processing. Othomosaics and

97 NDVI rasters for each date were derived by post-processing with Pix4Dmapper Pro (Pix4D SA, Lausanne,

98 Switzerland). The average ground sampling distance was $12.5 \mathrm{~cm}$ with an average geolocation root mean

99 square error (RMSE) of $2.3 \mathrm{~cm}$ (Table 1). Observations were resampled to match the spatial scale of the

100 image with the coarsest resolution, $13.43 \mathrm{~cm}$ from the July 1 image. We created a daily NDVI product for

101 the May 19 - July 20 period, NDVI ${ }_{\text {int }}$, by linearly interpolating NDVI observations from each pixel from

102 each UAV flight.

103 
105 Landsat NDVI calculations were made at 30-meter resolution using data from the Landsat 7 mission and 106 Google Earth Engine [35]. We used the maximum NDVI value for the calendar year to compare with yield 107 data from the combine harvester.

\subsection{Data Analysis}

\subsubsection{Unsupervised Classification}

111 We combined the four dates of UAV NDVI imagery into a single raster file for spatio-temporal 112 classification. We used k-means unsupervised classification in Erdas Imagine (Hexagon Geospatial, 113 Norcross, GA), with 50 initial classes. From these, we used the Grouping Tool to create three classes from 114 the 50 original classes using expert knowledge of the field (topography, geology, soil distribution, etc.) to 115 logically combine classes. We then imported the three-class classified map into ArcMap (Esri, Inc., 116 Redlands, CA), created masks for each group, and extracted the NDVI values for each of the four dates. 117 We averaged the NDVI values for each date and class to create four-date trajectories of average NDVI.

\subsubsection{Comparison of NDVI to yield data}

120 Georeferenced ('GPS-tagged') wheat yield and GPC measurements were made using a combine yield 121 monitor during harvest (Fig. S1). These data were cleaned using a Yield Editor tool (United States 122 Department of Agriculture, Washington D.C.) to adjust for sensor lag and missing values. To match the 123 footprint of the combine with observed NDVI values, we created $1 \times 12 \mathrm{~m}$ rectangular buffers around each 124 yield point, from which we extracted the average NDVI values from each date within the buffer polygon.

\subsection{Statistical Analysis}

127 We used Akaike's Information Criterion (AIC) to select amongst different linear models of yield and GPC 128 as a function of NDVI measured on the four different dates as well as NDVI int. $_{\text {Models were selected using }}$ 129 the dredge routine in the MuMIn package [36] in R [37]. 


\subsection{Spatial Analysis}

132 We calculated the change in total variance of NDVI that results from averaging with increasingly large

133 pixels to understand how variance is "averaged out" at coarser spatial scales, often called the 'grain' of the 134 image, not to be confused with the grain crop. NDVI varies between 0 and 1 in the absence of water bodies 135 and, if unimodal, can be modeled as a Beta distribution [38] as increasingly used for studies of plant cover 136 [39]. We fit Beta distribution parameters using observations from the original images and the spatially137 averaged images using maximum likelihood methods. We then calculated the change in information content 138 that results from spatial averaging using the Kullback-Leibler divergence $\left(\mathrm{D}_{\mathrm{KL}}\right)$ for the case of a Beta 139 distribution:

140 $D_{K L}=\ln \left(\frac{B\left(\alpha \prime, \beta^{\prime}\right)}{B(\alpha, \beta)}\right)+\left(\alpha-\alpha^{\prime}\right) \psi(\alpha)+\left(\beta-\beta^{\prime}\right) \psi(\beta)+\left(\alpha^{\prime}-\alpha+\beta^{\prime}-\beta\right) \psi(\alpha+\beta)$.

141 where $\alpha$ and $\beta$ are the shape parameters of the Beta distribution of NDVI from the original image, $\alpha^{\prime}$ and

$142 \beta^{\prime}$ are the parameters of the Beta distribution after spatial averaging, B is the beta function, and $\psi(x)$ is the 143 digamma function:

$144 \quad \psi(x)=\frac{d}{d x} \ln (\Gamma(x))$

145 where $\Gamma(x)$ is the gamma function.

146 To quantify scaling relationships within the field on the different measurement days we calculated the 147 radially-averaged power spectral density (Y) of each NDVI image [40,41] with Fatiando a Terra v0.5 for 148 Python [42], and interpreted the resulting spectra in terms of its power law exponent $b[43,44]$ :

$149 \quad \mathrm{Y}=c k^{\mathrm{b}}$

150 where $k$ is scale $\left(\mathrm{m}^{-1}\right)$ and $c$ is a normalization constant.

\section{3. Results}


154 NDVI averaged $0.91 \pm 0.014$ on May $19,0.88 \pm 0.025$ on June $8,0.44 \pm 0.063$ on July 12 , and $0.27 \pm 0.011$

155 on July 20 (Figure 2). Unsupervised classification distinguished different parts of the field as having

156 relatively high, medium, or low NDVI trajectories across the growing season (Figure 3). This classification

157 - and the images themselves - reveal NDVI patterns with different characteristic length scales from

158 centimeters to hundreds of meters, with implications for yield, GPC, and within-field management

159 opportunities.

160

1613.2 Relationships between NDVI and wheat yield

162 NDVI measurements from each UAV flyover were significantly related to yield $(P<0.05$, Figure 4$)$, but

163 Landsat NDVI observations only explained $1 \%$ of its variability. NDVI measurements from June 8

$164\left(\mathrm{NDVI}_{\mathrm{June}}\right)$ and July $12\left(\mathrm{NDVI}_{\mathrm{July} 12}\right)$ explained $20 \%$ or more of the variability of wheat yield (Figure 2 top),

165 but $\mathrm{NDVI}_{\mathrm{May} 19}$ and $\mathrm{NDVI}_{\mathrm{July} 20}$ explained less than $14 \%$. Linear model selection using AIC indicated that a

166 model that summed NDVI measurements from all periods ( $\Sigma$ NDVI) explained nearly $25 \%$ of the variability

167 in yield (Figure 5A) and represented 59\% of the weight - the relative likelihood - across all models tested.

168 Assuming a linear relationship between each NDVI observation and time, creating a NDVI product for

169 every day, and summing the subsequent interpolated values did not improve the model (Figure 5B). The

170 model with the highest $R^{2}$,

171 Yield $=-11520+963.2 \times \mathrm{NDVI}_{\text {July } 1}+3750 \times \mathrm{NDVI}_{\text {July20 }}+7254 \times \mathrm{NDVI}_{\text {June } 8}+8617 \times \mathrm{NDVI}_{\text {May19, }}$,

172 explained $26 \%$ of the observed variability in yield, similar to the linear model as a function of $\Sigma$ NDVI. In

173 other words, a model with four discrete NDVI measurements explained slightly more variability in yield

174 than a measurement that included only their sum but was penalized by the AIC analysis for having more 175 parameters.

176 
$178 \mathrm{NDVI}_{\mathrm{May} 19}$ explained $30 \%$ of the variability in GPC. NDVI $\mathrm{July}_{19}$ was also significantly related to GPC $(P<$ 1790.05 ) but only explained 6\% of its variability (Fig. 6). Model selection using AIC chose a model that 180 includes $\mathrm{NDVI}_{\mathrm{May} 19}, \mathrm{NDVI}_{\mathrm{July} 20}$, and a negative relationship with $\mathrm{NDVI}_{\text {June } 8}$, but not $\mathrm{NDVI}_{\mathrm{July} 12}$ :

$181 \mathrm{GPC}=-25.20+27.9100 \times \mathrm{NDVI}_{\mathrm{July} 20}-19.4100 \times \mathrm{NDVI}_{\mathrm{June} 8}+52.36 \times \mathrm{NDVI}_{\text {May19. }}$.

182 This model explained $40 \%$ of the variability in GPC and represented 59\% of the weight across all models

183 tested (Fig. 7). The remaining 41\% weight was represented by a model that includes NDVI on all dates

184 including a negative term for $\mathrm{NDVI}_{\text {June8, }}$ meaning that the most parsimonious model would be represented

185 by a combination of $59 \%$ of the model that included three NDVI dates and $41 \%$ of the model that included

186 all four. We also explored Red Edge as an alternative to NDVI, but this explained about $1 \%$ less of the

187 variability in GPC and likewise did not improve the model for yield.

188

\subsection{Interpreting the NDVI observations as a function of spatial scale}

190 The rich spatial patterns of NDVI observations (Figs. 2 \& 3) led us to question how much of the variability 191 in their distributions (Fig. 8A) was 'averaged out' by Landsat that provided data on $30 \mathrm{~m}$ scales and the 192 harvester that provided yield and GPC data on $1 \times 12 \mathrm{~m}$ scales. Total variance monotonically decreased as 193 spatial grain increased for each image (Fig. 8B) but with different slopes and degrees of nonlinearity such 194 that the role of averaging may be better envisioned by the loss of variance as a function of scale (Fig. 8C). 195 Over $50 \%(75 \%)$ of the total variance of the $\mathrm{NDVI}_{\text {May19 }}\left(\mathrm{NDVI}_{\mathrm{July} 20}\right)$ image was lost when aggregating to 196 the scale of the harvester and Landsat, but only $1 / 3$ of the total variance of the $\mathrm{NDVI}_{\mathrm{June}}$ image was lost at 197 the $30 \mathrm{~m}$ Landsat scale. The earlier NDVI measurements (May 19 and June 8) had substantial negative 198 skew (Fig. 8D), indicating the presence of areas in the field with far lower NDVI than the mean that are 199 likely candidates for management intervention. This skewness was also 'averaged out' at larger spatial 200 scales, especially the $\mathrm{NDVI}_{\mathrm{May} 19}$ image whose skewness changed from -4 to -0.5 upon averaging to the 201 Landsat scale.

202 The $\mathrm{D}_{\mathrm{KL}}$ quantifies the change in information content between the original and spatially-averaged 203 images. It increased rapidly at spatial scales larger than $30 \mathrm{~m}$ (Figure 9A) but was less than $0.15(0.25)$ at 
204 the harvester (Landsat) scale for the NDVI $\mathrm{May}_{19}, \mathrm{NDVI}_{\mathrm{June}}$, and $\mathrm{NDVI}_{\mathrm{July}}$ images. (The $\mathrm{D}_{\mathrm{KL}}$ for the $205 \mathrm{NDVI}_{\mathrm{July} 20}$ image was consistently much larger and is not shown in the figures for clarity.) Changes to the $206 \alpha$ parameter (i.e. $\alpha$ ) dominated $\mathrm{D}_{\mathrm{KL}}$ for the May 19 and June 8 images as spatial grain became larger, and 207 changes to the $\beta$ parameter (i.e. $\beta$ ') dominated $\mathrm{D}_{\mathrm{KL}}$ for the July 1 image.

208 The power law exponent (i.e. b) of the radially-averaged power-density spectra was constant at b $209=2.3(2.4)$ for the June 8 (July 1) images across all scales (Fig. 10) noting that the July 1 image has more 210 total variance than the June 8 image (Fig. 8B). There was notable variability in all spectra and a scale break 211 in the May 19 and July 20 images on the order of $6 \mathrm{~m}^{-1}$ (i.e. $\sim 17 \mathrm{~cm}$ ) and b decreased faster at spatial 212 frequencies larger than this value, especially in the May 19 image when it decreased from -2 to -3.2 (Fig.

213 10). There was also notable variability in all spectra at $20.6 \mathrm{~m}^{-1}$, about $5 \mathrm{~cm}$ (Fig. 10). Some of the minor 214 peaks at lower spatial frequencies present in the other images were absent in the June 8 image which 215 suffered from less information loss at larger spatial scales than the other images (Fig. 8C).

\section{4. Discussion}

218 Detailed observations are expected to provide agricultural producers with the knowledge and tools to further 219 develop prescriptive, variable-rate management practices. Because UAV mapping is becoming widespread, 220 it is essential to explore the boundaries of what is practical and necessary to improve agricultural 221 management and sustainable production. We discuss how the interpretation of NDVI at fine spatial scales 222 can provide producers with the correct amount of information - not too much and not too little - to 223 understand within-field variability.

\section{4.1 Spatio-temporal patterns of NDVI}

225 Areas of consistently higher NDVI values through the growing season were located in the SW portion of 226 the study field in an area of lower topography that likely benefits from water drainage in characteristically 227 dry north-central Montana (Figs. 1 \& 3). There was an E-W swath of higher NDVI values that was identified 228 as an old fence line where blowing soil likely accumulated in prior decades and improved fertility. Areas 229 of moderately high NDVI values were widely distributed throughout the field and were clearly observed 
230 along thin linear features, especially in the NE portion of the field, thought to be associated with the edges

231 of shale cracks and improved plant access to deeper soils. Areas of consistently lower NDVI values through

232 the growing season were primarily clustered in the northern, higher elevation portion of the field, likely

233 associated with lower water retention and thinner soils. Such observations can guide further soil sampling,

234 which are key to further improve yield prediction [45]. Note that these patterns are not readily apparent to

235 the human eye, to which the field appears largely homogeneous (Fig. 1B).

236 From this analysis it is apparent that NDVI observations provide rich spatial information to

237 producers, but all four UAV flights were necessary to identify key features; note for example that many of

238 the features identified by the unsupervised classification (Fig. 3) were not apparent in the May 19 image

239 (Fig. 2A). NDVI measured early in the growing season can predict eventual yield [46] but feature

240 identification relied on all of the images, as did the best model for yield prediction (Figs. $4 \& 5$ ). NDVI

241 from the May 19 image alone was able to explain 30\% of the variability in GPC (Fig. 6A), and additional

242 observations increased predictive power by 10\% (Fig. 7). Management interventions during earlier dates,

243 especially during the wheat heading stage, are candidates for $\mathrm{N}$ top dressing, the major within-season

244 management correction that producers can take to enhance GPC [47]. In other words, all of the images

245 produced information that can be useful for understanding the idiosyncrasies of an individual field but

246 earlier information can guide management. One potential approach to maximize information and minimize

247 effort is to make multiple flyovers during initial investigations to understand the properties of individual

248 fields, then reserve flights in future years for early periods of the growing season to identify deficiencies

249 from expected crop growth patterns.

$250 \quad 4.2$ NDVI as a function of spatial scale

251 It is readily apparent that the high-resolution information from the UAV flyovers greatly exceeds the yield

252 and GPC information that the harvester is able to provide, creating a scale mismatch that can be understood

253 by exploring the consequences of spatial averaging of the NDVI images. At least $22 \%$ (June 8 ) and up to

$25475 \%$ (July 20) of the observed NDVI variance is averaged out at the scale of the harvester, $12 \mathrm{~m}$ (Fig. 8B-

255 C), which makes much of the information content of the UAV NDVI images irrelevant for understanding 
yield and GPC collected at coarser scales. Notably, many of the underperforming areas visible early in the

257 May 19 image by its negative skew (Fig. 8D) were averaged out at larger spatial scales. That being said, 258 the practical consequences of high skewness in the case of the study field may be unimportant; less than

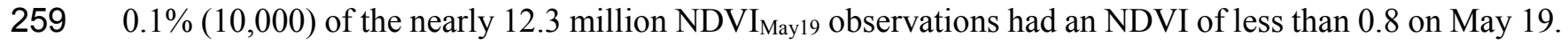
260 Instead of dwelling on information loss with spatial averaging, there are many features of NDVI at coarser 261 spatial scales that might be considered promising for a simpler description of its spatial variability.

In addition to the relatively low loss of variance in the June 8 image, the $\mathrm{D}_{\mathrm{KL}}$ analysis reveals low information loss compared to the other images (Fig. 9A). This means that the shape of the Beta distribution,

264 as defined by its parameters (Fig. 9B-C), was largely maintained upon spatial averaging. In other words, 265 parameters fit from data at coarser spatial scales are a reasonably good approximation for those fit from 266 data at finer scales. It helps that NDVI in our case follows unimodal distributions in all cases.

This opens the possibility for an efficient description of the variability of fine scale data from coarse scale data, as also revealed by the scaling analysis (Figure 10) which demonstrates that NDVI from all images follows a power law scaling relationship of $\mathrm{b} \sim-2$ at spatial scales larger than $\sim 0.5 \mathrm{~m}$. The June 8 and July 1 images had a common scaling relationship of $\mathrm{b} \sim-2$ and across all scales. The May 19 image

271 follows an even steeper power law relationship $(\mathrm{b} \sim-3.2)$ at spatial scales smaller than $\sim 0.1 \mathrm{~m}$ suggesting

272 that exponentially less information is present at high frequencies and the dominant modes of variability in 273 the field are at relatively low spatial frequencies, i.e. large spatial scales.

277 and we found lower descriptive power when using red edge (not shown). Moving beyond NDVI, 278 multispectral data have proven effective for predicting wheat yield [51,52], GPC [53,54], senescence [55], 279 and even detecting diseases [56]. Combined, results suggest that not all spectral data are necessary for a 280 concise description of yield and GPC, nor are all spatial data. Going forward, we recommend an experiment 281 that 'oversamples' within-field wheat spectral reflectance at hyperspectral, 'hypertemporal', and 
hyperspatial resolution to quantify the information that is necessary to predict yield and GPC, as well as the

283 information that is unnecessary. By quantifying the benefits, but also the costs, of information acquisition,

284 producers can gain a richer understanding of the most cost-effective information to collect to manage wheat

285 yields and GPC and continue feeding a growing populace.

\section{Acknowledgements}

288

This work was supported by the Montana Wheat and Barley Committee. PCS acknowledges support from the Alexander von Humboldt-Foundation, the NSF Division of Environmental Biology grant \#1552976, and the University of Wisconsin - Madison. We thank Bruce Maxwell, Adam Cook, Gabriel Bromley, James Irvine, and Skylar Williams for technical support, and Chuck Merja for ongoing research support

292 and inspiration.

\section{References}

1. Miller MP, Singer MJ, Nielsen DR. Spatial variability of wheat yield and soil properties on complex hills. Soil Sci Soc Am J. 1988;52: 1133.

2. Raun WR, Solie JB, Johnson GV, Stone ML, Lukina EV, Thomason WE, et al. In-season prediction

3. Aparicio N, Villegas D, Casadesus J, Araus JL, Royo C. Spectral vegetation indices as

4. Serrano L, Filella I, Peñuelas J. Remote sensing of biomass and yield of winter wheat under different nitrogen supplies. Crop Sci. 2000;40: 723.

5. Lopes MS, Reynolds MP. Stay-green in spring wheat can be determined by spectral reflectance measurements (normalized difference vegetation index) independently from phenology. J Exp Bot. 2012;63: 3789-3798.

6. Macnack N, Khim BC, Mullock J, Raun W. In-season prediction of nitrogen use efficiency and grain protein in winter wheat (Triticum aestivumL.). Communications in Soil Science and Plant Analysis. 2014. pp. 2480-2494. doi:10.1080/00103624.2014.904337

7. Gozdowski D, Stępień M, Panek E, Varghese J, Bodecka E, Rozbicki J, et al. Comparison of winter wheat NDVI data derived from Landsat 8 and active optical sensor at field scale. Remote Sensing Applications: Society and Environment. 2020. p. 100409. doi:10.1016/j.rsase.2020.100409

8. Bégué A, Arvor D, Bellon B, Betbeder J, de Abelleyra D, Ferraz RPD, et al. Remote sensing and cropping practices: A review. Remote Sensing. 2018. p. 99. doi:10.3390/rs10010099 
9. Kasampalis D, Alexandridis T, Deva C, Challinor A, Moshou D, Zalidis G. Contribution of remote sensing on crop models: A review. Journal of Imaging. 2018. p. 52. doi:10.3390/jimaging4040052

10. Bale MD, Ryan ME. Wheat protein premiums and price differentials. American Journal of Agricultural Economics. 1977. pp. 530-532. doi:10.2307/1239655

11. Bongiovanni RG, Robledo CW, Lambert DM. Economics of site-specific nitrogen management for protein content in wheat. Computers and Electronics in Agriculture. 2007. pp. 13-24. doi:10.1016/j.compag.2007.01.018

12. Wright DL, Philip Rasmussen V, Douglas Ramsey R, Baker DJ, Ellsworth JW. Canopy reflectance estimation of wheat nitrogen content for grain protein management. GIScience \& Remote Sensing. 2004. pp. 287-300. doi:10.2747/1548-1603.41.4.287

13. Asseng S, Martre P, Maiorano A, Rötter RP, O'Leary GJ, Fitzgerald GJ, et al. Climate change impact and adaptation for wheat protein. Glob Chang Biol. 2019;25: 155-173.

14. Bogard M, Allard V, Brancourt-Hulmel M, Heumez E, Machet J-M, Jeuffroy M-H, et al. Deviation from the grain protein concentration-grain yield negative relationship is highly correlated to postanthesis N uptake in winter wheat. J Exp Bot. 2010;61: 4303-4312.

15. Simmonds NW. The relation between yield and protein in cereal grain. Journal of the Science of Food and Agriculture. 1995. pp. 309-315. doi:10.1002/jsfa.2740670306

16. Whelan BM, Taylor JA, Hassall JA. Site-specific variation in wheat grain protein concentration and wheat grain yield measured on an Australian farm using harvester-mounted on-the-go sensors. Crop and Pasture Science. 2009. p. 808. doi:10.1071/cp08343

17. Zhao C, Liu L, Wang J, Huang W, Song X, Li C. Predicting grain protein content of winter wheat using remote sensing data based on nitrogen status and water stress. Int J Appl Earth Obs Geoinf. 2005;7: 1-9.

18. Rodrigues FA, Blasch G, BlasDefournych P, Ivan Ortiz-Monasterio J, Schulthess U, Zarco-Tejada PJ, et al. Multi-temporal and spectral analysis of high-resolution hyperspectral airborne imagery for precision agriculture: Assessment of Wheat Grain Yield and Grain Protein Content. Remote Sensing. 2018. p. 930 . doi: $10.3390 /$ rs 10060930

19. Zhao, Zhao, Song, Yang, Li, Zhang, et al. Monitoring of nitrogen and grain protein content in winter wheat based on Sentinel-2A data. Remote Sensing. 2019. p. 1724. doi:10.3390/rs11141724

20. Xu X, Teng C, Zhao Y, Du Y, Zhao C, Yang G, et al. Prediction of Wheat grain protein by coupling multisource remote sensing imagery and ECMWF data. Remote Sensing. 2020. p. 1349. doi:10.3390/rs12081349

21. Shou L, Jia L, Cui Z, Chen X, Zhang F. Using high-resolution satellite imaging to evaluate nitrogen status of winter wheat. Journal of Plant Nutrition. 2007. pp. 1669-1680. doi:10.1080/01904160701615533

22. Feng M-C, Xiao L-J, Zhang M-J, Yang W, Ding G-W. Integrating remote sensing and GIS for prediction of winter wheat (Triticum aestivum) protein contents in Linfen (Shanxi), China. PLoS One. 2014;9: e80989.

23. Tan C, Zhou X, Zhang P, Wang Z, Wang D, Guo W, et al. Predicting grain protein content of field- 
grown winter wheat with satellite images and partial least square algorithm. PLoS One. 2020;15: $\mathrm{e} 0228500$.

24. Tan C, Guo W, Wang J. Predicting grain protein content of winter wheat based on landsat TM images and leaf nitrogen Content. 2011 International Conference on Remote Sensing, Environment and Transportation Engineering. 2011. doi:10.1109/rsete.2011.5965478

25. Wang L, Tian Y, Yao X, Zhu Y, Cao W. Predicting grain yield and protein content in wheat by fusing multi-sensor and multi-temporal remote-sensing images. Field Crops Research. 2014. pp. 178-188. doi:10.1016/j.fcr.2014.05.001

26. Lai YR, Pringle MJ, Kopittke PM, Menzies NW, Orton TG, Dang YP. An empirical model for prediction of wheat yield, using time-integrated Landsat NDVI. International Journal of Applied Earth Observation and Geoinformation. 2018. pp. 99-108. doi:10.1016/j.jag.2018.07.013

27. Magney TS, Eitel JUH, Huggins DR, Vierling LA. Proximal NDVI derived phenology improves inseason predictions of wheat quantity and quality. Agricultural and Forest Meteorology. 2016. pp. 46-60. doi:10.1016/j.agrformet.2015.11.009

28. Xue L-H, Li-Hong XUE, Wei-Xing CAO, Yang L-Z. Predicting grain yield and protein content in winter wheat at different $\mathrm{N}$ supply levels using canopy reflectance Spectra. Pedosphere. 2007. pp. 646-653. doi:10.1016/s1002-0160(07)60077-0

29. Anderegg J, Yu K, Aasen H, Walter A, Liebisch F, Hund A. Spectral vegetation indices to track senescence dynamics in diverse wheat germplasm. Front Plant Sci. 2019;10: 1749.

30. Zhang C, Kovacs JM. The application of small unmanned aerial systems for precision agriculture: a review. Precis Agric. 2012;13: 693-712.

31. Fernández E, Gorchs G, Serrano L. Use of consumer-grade cameras to assess wheat N status and grain yield. PLoS One. 2019;14: e0211889.

32. Aasen H, Kirchgessner N, Walter A, Liebisch F. PhenoCams for Field Phenotyping: Using very high temporal resolution digital repeated photography to investigate interactions of growth, phenology, and harvest traits. Front Plant Sci. 2020;11: 593.

33. Luschei EC, Van Wychen LR, Maxwell BD, Bussan AJ, Buschena D, Goodman D. Implementing and conducting on-farm weed research with the use of GPS. Weed Sci. 2001;49: 536-542.

34. Haley SD, Johnson JJ, Westra PH, Peairs FB, Stromberger JA, Hudson EE, et al. Registration of "Brawl CL Plus" wheat. Journal of Plant Registrations. 2012. pp. 306-310. doi:10.3198/jpr2011.12.0673crc

35. Gorelick N, Hancher M, Dixon M, Ilyushchenko S, Thau D, Moore R. Google Earth Engine: Planetary-scale geospatial analysis for everyone. Remote Sens Environ. 2017;202: 18-27.

36. Barton K. Package "MuMIn." CRAN; 2018. Available: $\mathrm{ftp} / / / 155.232 .191 .229 / \mathrm{cran} / \mathrm{web} /$ packages/MuMIn/MuMIn.pdf

37. R Core Team. R: A Language and Environment for Statistical Computing. 2017. Available: https://www.R-project.org/

38. Stoy PC, Williams M, Disney M, Prieto-Blanco A, Huntley B, Baxter R, et al. Upscaling as 
ecological information transfer: a simple framework with application to Arctic ecosystem carbon

39. Damgaard CF, Irvine KM. Using the beta distribution to analyze plant cover data. Journal of

40. Stoy PC, Quaife T. Probabilistic Downscaling of remote sensing data with applications for multiscale biogeochemical flux modeling. PLoS One. 2015;10: e0128935.

41. Poveda G, Salazar LF. Annual and interannual (ENSO) variability of spatial scaling properties of a vegetation index (NDVI) in Amazonia. Remote Sensing of Environment. 2004. pp. 391-401. doi:10.1016/j.rse.2004.08.001

42. Uieda L, Oliveira V, Barbosa V. Modeling the Earth with Fatiando a Terra. Proceedings of the 12th Python in Science Conference. 2013. doi:10.25080/majora-8b375195-010

43. Marquet PA, Quiñones RA, Abades S, Labra F, Tognelli M, Arim M, et al. Scaling and power-laws in ecological systems. J Exp Biol. 2005;208: 1749-1769.

44. West GB. The origin of universal scaling laws in biology. Physica A: Statistical Mechanics and its Applications. 1999. pp. 104-113. doi:10.1016/s0378-4371(98)00639-6

45. Pantazi XE, Moshou D, Alexandridis T, Whetton RL, Mouazen AM. Wheat yield prediction using machine learning and advanced sensing techniques. Computers and Electronics in Agriculture. 2016. pp. 57-65. doi:10.1016/j.compag.2015.11.018

46. Marti J, Bort J, Slafer GA, Araus JL. Can wheat yield be assessed by early measurements of Normalized Difference Vegetation Index? Annals of Applied Biology. 2007. pp. 253-257. doi:10.1111/j.1744-7348.2007.00126.x

47. Szentpétery Z, Jolánkai M, Kleinheincs C, Szöllösi G. Effect of nitrogen top-dressing on winter wheat. Cereal Research Communications. 2005. pp. 619-626. doi:10.1556/crc.33.2005.2-3.128

48. Jia L, Yu Z, Li F, Gnyp M, Koppe W, Bareth G, et al. Nitrogen status estimation of winter wheat by using an IKONOS satellite image in the North China Plain. Computer and Computing Technologies in Agriculture V. 2012. pp. 174-184. doi:10.1007/978-3-642-27278-3_19

49. Hansen PM, Jørgensen JR, Thomsen A. Predicting grain yield and protein content in winter wheat and spring barley using repeated canopy reflectance measurements and partial least squares regression. The Journal of Agricultural Science. 2002. pp. 307-318. doi:10.1017/s0021859602002320

50. Aboelghar M, Ali A-R, Arafat S. Spectral wheat yield prediction modeling using SPOT satellite imagery and leaf area index. Arabian Journal of Geosciences. 2014. pp. 465-474. doi:10.1007/s12517-012-0772-6

51. Ahlrichs JS, Bauer ME. Relation of agronomic and multispectral reflectance characteristics of spring wheat canopies 1. Agronomy Journal. 1983. pp. 987-993. doi:10.2134/agronj1983.00021962007500060029x

52. Hassan MA, Yang M, Rasheed A, Yang G, Reynolds M, Xia X, et al. A rapid monitoring of NDVI across the wheat growth cycle for grain yield prediction using a multi-spectral UAV platform. Plant Sci. 2019;282: 95-103. 
53. Astaoui G, Dadaiss JE, Sebari I, Benmansour S, Mohamed E. Mapping wheat dry matter and nitrogen content dynamics and estimation of wheat uield using UAV multispectral imagery machine learning and a variety-based approach: Case study of Morocco. AgriEngineering. 2021. pp. 29-49. doi:10.3390/agriengineering3010003

434 54. Zhou X, Kono Y, Win A, Matsui T, Tanaka TST. Predicting within-field variability in grain yield and protein content of winter wheat using UAV-based multispectral imagery and machine learning approaches. Plant Production Science. 2021. pp. 137-151. doi:10.1080/1343943x.2020.1819165

55. Hassan M, Yang M, Rasheed A, Jin X, Xia X, Xiao Y, et al. Time-series multispectral indices from unmanned aerial vehicle imagery reveal senescence rate in bread wheat. Remote Sensing. 2018. p. 809. doi:10.3390/rs10060809

56. Franke J, Menz G. Multi-temporal wheat disease detection by multi-spectral remote sensing. Precision Agriculture. 2007. pp. 161-172. doi:10.1007/s11119-007-9036-y 
442 Tables

443 Table 1. Average ground sampling distance (GSD, i.e. 'pixel size') and the root mean square error 444 (RMSE) of the ground control point used for UAV imagery on each date.

\begin{tabular}{|l|l|l|}
\hline Date (2016) & GSD (cm) & Geolocation RMSE (cm) \\
\hline May 19 & 11.03 & 3.6 \\
\hline June 8 & 12.48 & 1.4 \\
\hline July 1 & 13.43 & 2.6 \\
\hline July 20 & 13.13 & 1.7 \\
\hline
\end{tabular}

445 


\section{Figures}

447 Figure 1. (top) A map of the study area; a winter wheat field near Sun River, Montana, USA (top) and

448 (botom) a photograph of the eddy covariance tower taken on May 4, 2016 (Image credit: Dr. James

449 Irvine). World Imagery: Esri, DigitalGlobe, GeoEye, i-cubed, USDA FSA, USGS, AEX, Getmapping,

450 Aerogrid, IGN, IGP, swisstopo, and the GIS User Community. World Topo Map: Esri, DeLorme, HERE,

451 TomTom, Intermap, increment P Corp., GEBCO, USGS, FAO, NPS, NRCAN, GeoBase, IGN, Kadaster

452 NL, Ordnance Survey, Esri Japan, METI, Esri China (Hong Kong), swisstopo, MapmyIndia, and the GIS

453 User Community.

455 Figure 2. The observed normalized difference vegetation index (NDVI) in a winter wheat field near Sun 456 River, Montana for four measurement dates in 2016.

458 Figure 3. Results of an unsupervised classification of NDVI into relatively high, medium, and low NDVI 459 classes.

461 Figure 4. The relationship between the normalized difference vegetation index (NDVI) measured by an 462 unmanned aerial vehicle on four dates and wheat yield in a winter wheat field near Sun River, MT, USA.

464 Figure 5. The relationship between winter wheat yield and the sum of unmanned aerial vehicle 465 measurements of the normalized difference vegetation index ( $\Sigma$ NDVI) for four measurement dates in a 466 winter wheat field in Montana, USA (A, see Figure 4). The relationship between yield and the sum of daily 467 NDVI from May 19, 2016 until July 20, 2016 created with a linear interpolation of NDVI measurements $468\left(\Sigma \mathrm{NDVI}_{\mathrm{int}}\right)$ across the four measurement dates.

470 Figure 6. The relationship between the normalized difference vegetation index (NDVI) measured by an 471 unmanned aerial vehicle and grain protein content in a winter wheat field near Sun River, MT, USA. 
472 Relationships that are not significant at the $P<0.05$ level are not plotted.

473

474 Figure 7. The relationship between protein content (\%) and the best-fit linear model of all identified using

475 Akaike's Information Criterion: Protein $=-25.20+27.9100 \times \mathrm{NDVI}_{\mathrm{July} 20}-19.4100 \times \mathrm{NDVI}_{\mathrm{June}}+52.36$

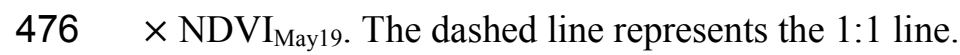

477

478 Figure 8: The distribution of the NDVI images (A) and variance (B), loss of variance (C), and skewness

479 (D) of each NDVI image as a function of spatial scale. The $30 \mathrm{~m}$ length scale of Landsat (dashed line) and

480 the $12 \mathrm{~m}$ length scale of the harvester (dotted line) are indicated for reference.

481

482 Figure 9: The change in Kullback-Leibler divergence $\left(\mathrm{D}_{\mathrm{KL}}, \mathrm{A}\right)$, the $\alpha$ parameter of the Beta distribution $\left(\alpha^{\prime}\right.$, $483 \mathrm{~B})$, and the $\beta$ parameter of the Beta distribution $(\beta, C)$ of observed NDVI as a function of spatial scale.

485 Figure 10: The radially-averaged power density spectra (PDS) of each NDVI image with the power law 486 exponent $b$ for values less than $2 \mathrm{~m}^{-1}$ (left) and greater than $10 \mathrm{~m}^{-1}$ (right). 

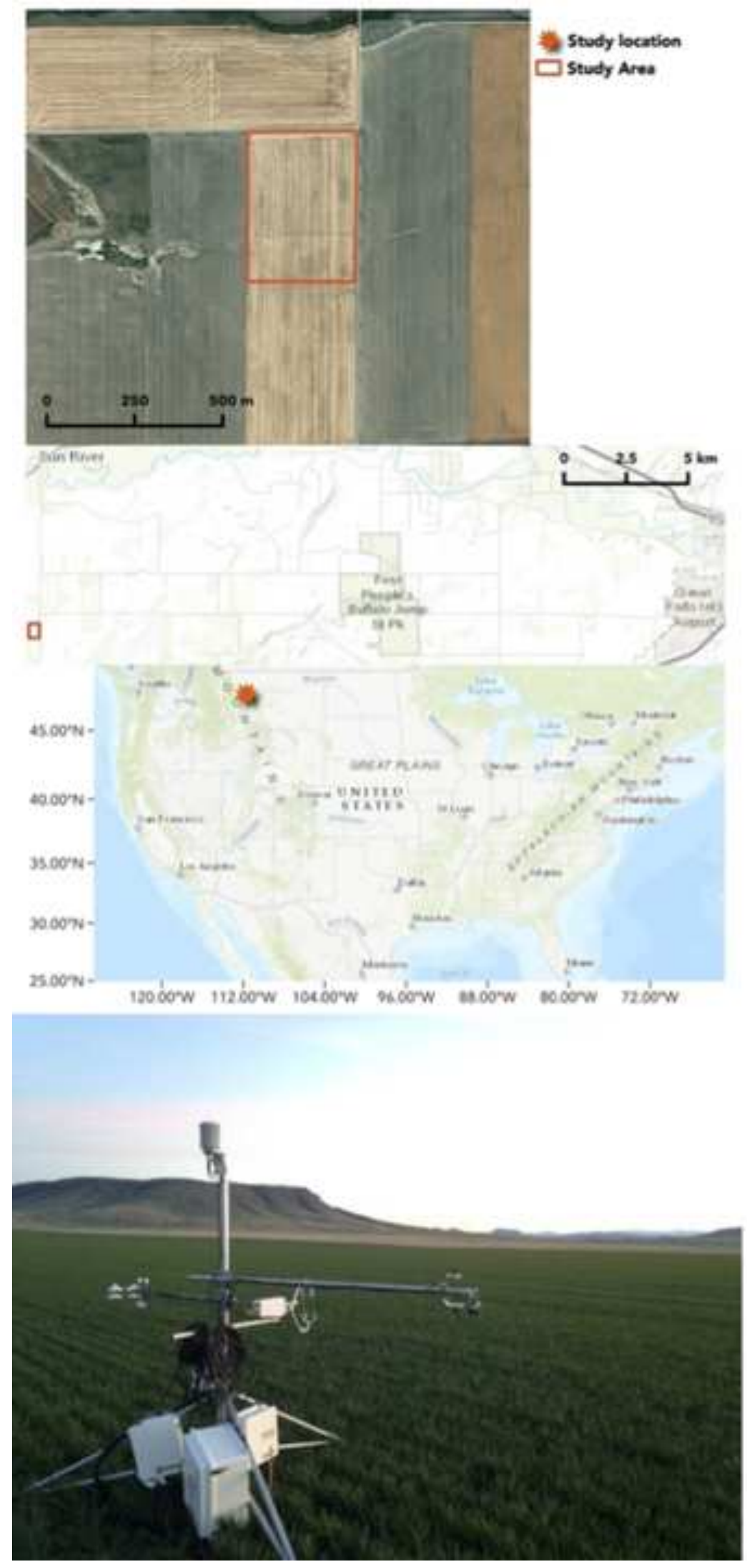


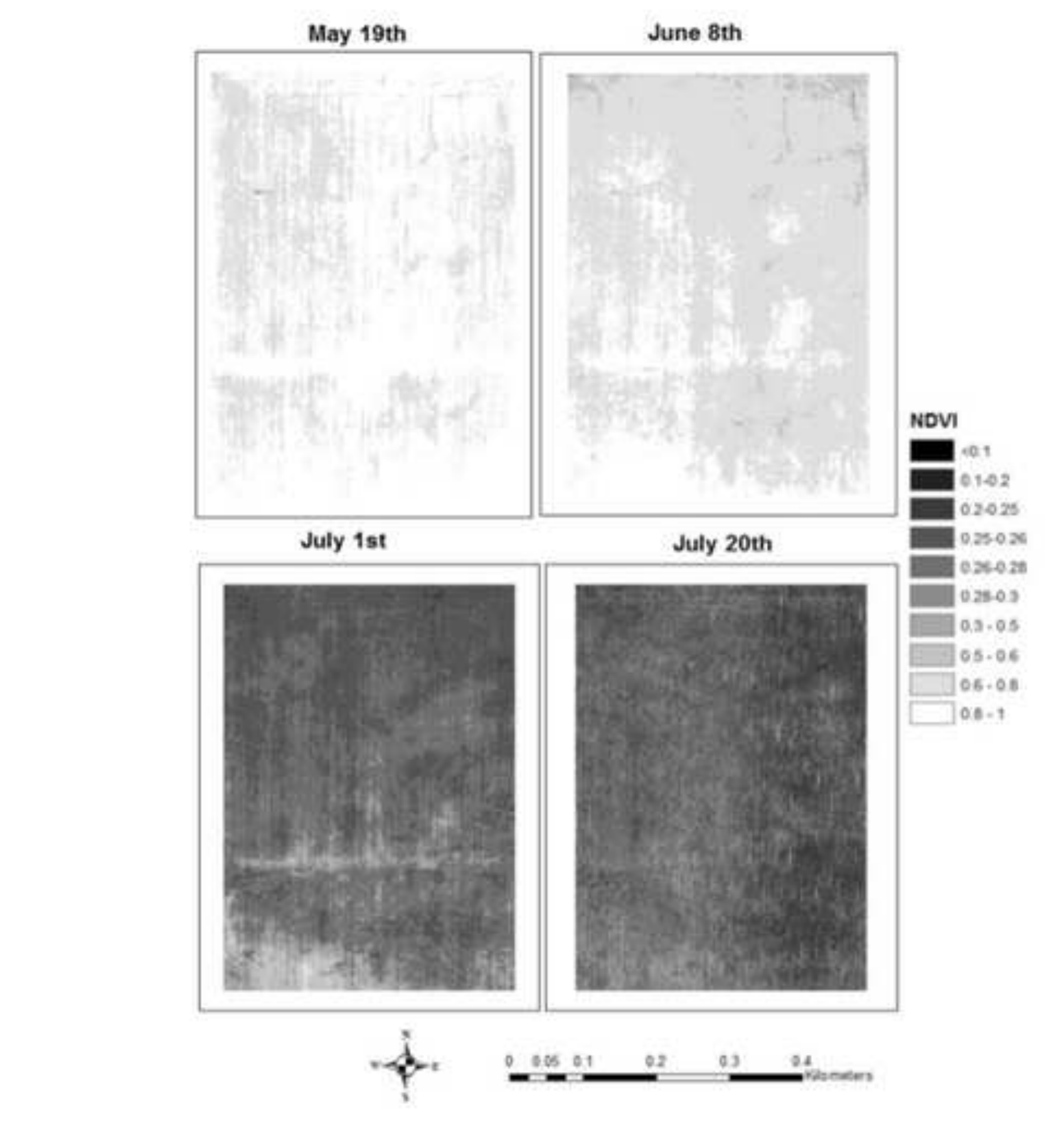

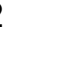

\section{Figure} .

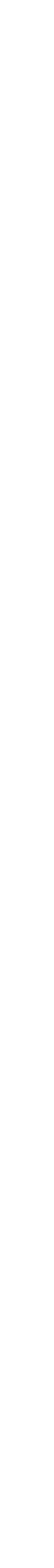



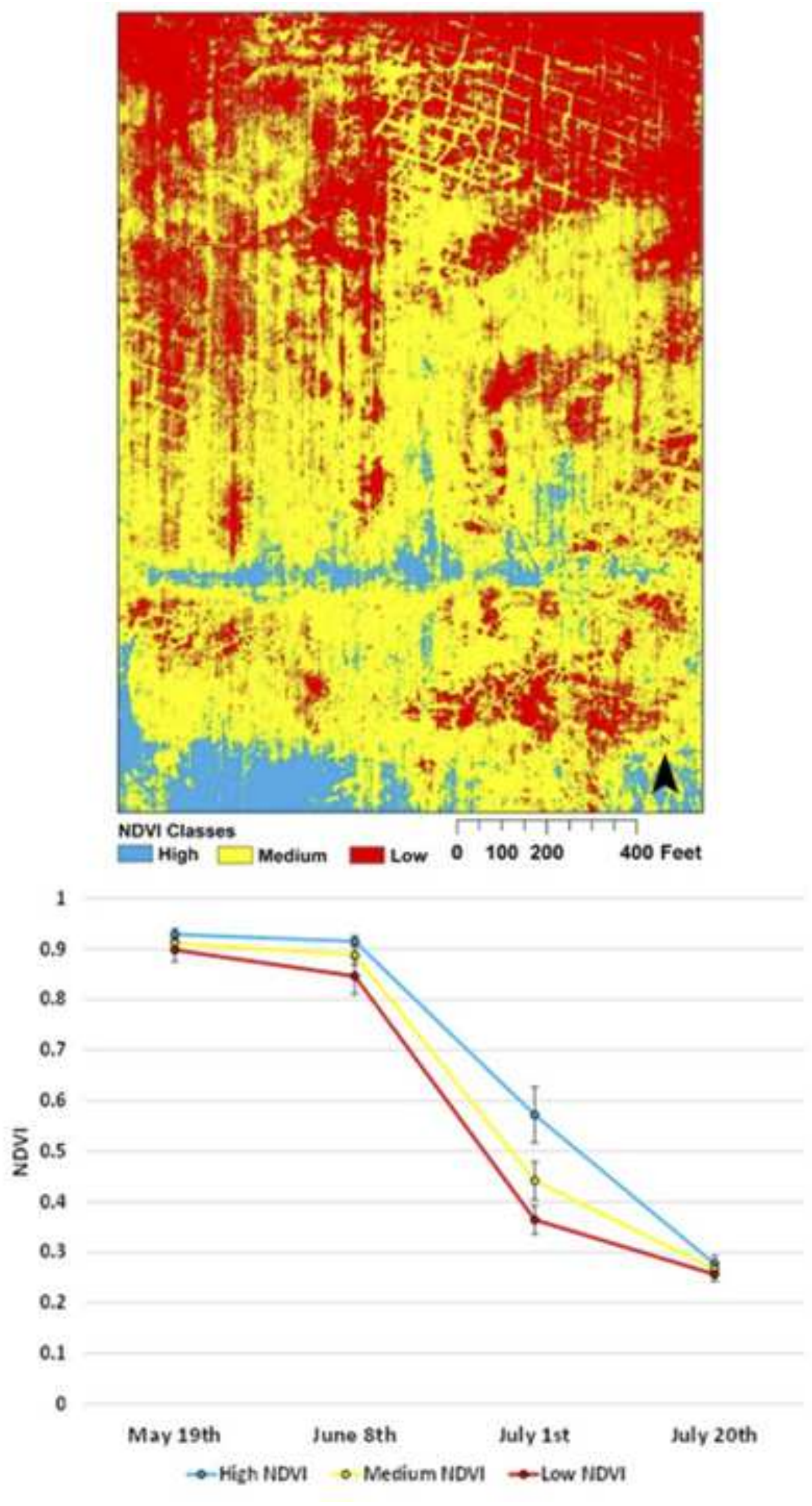

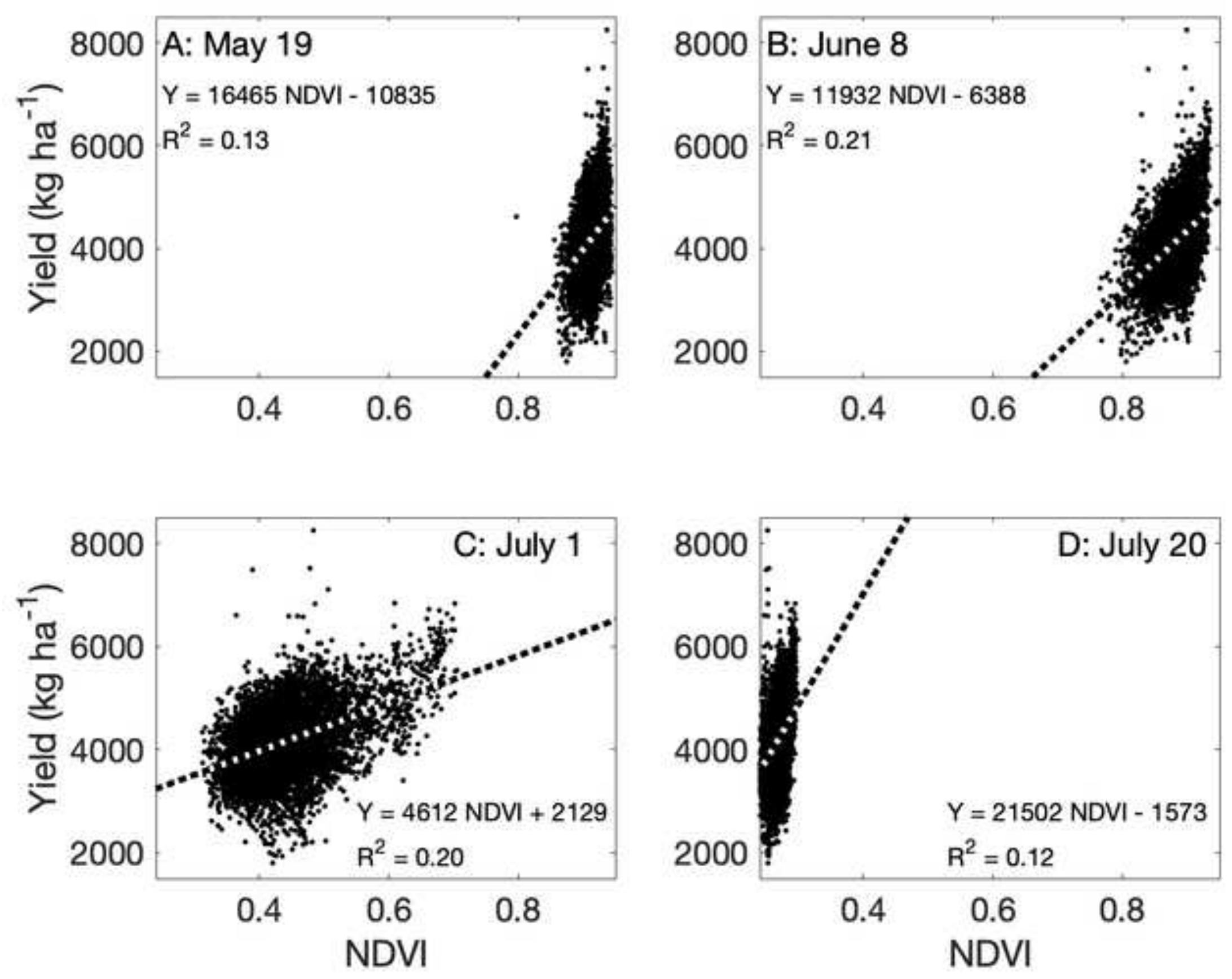

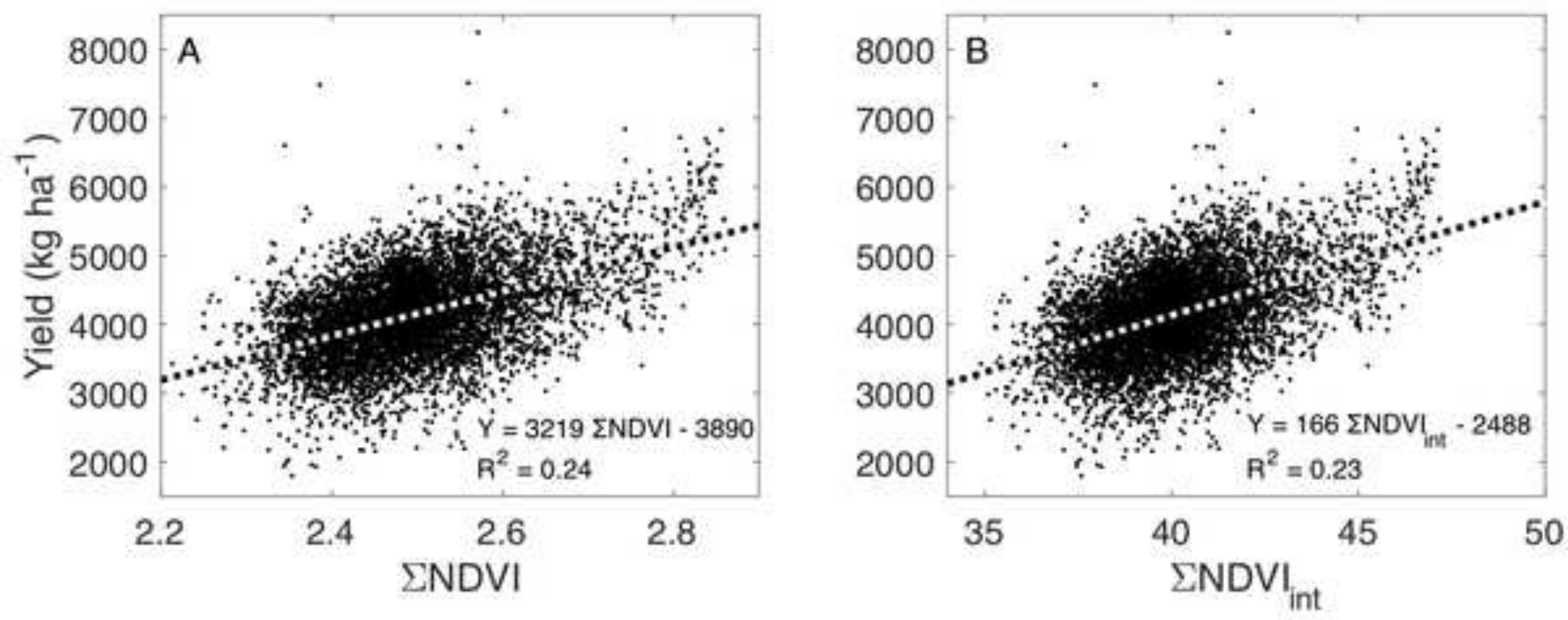

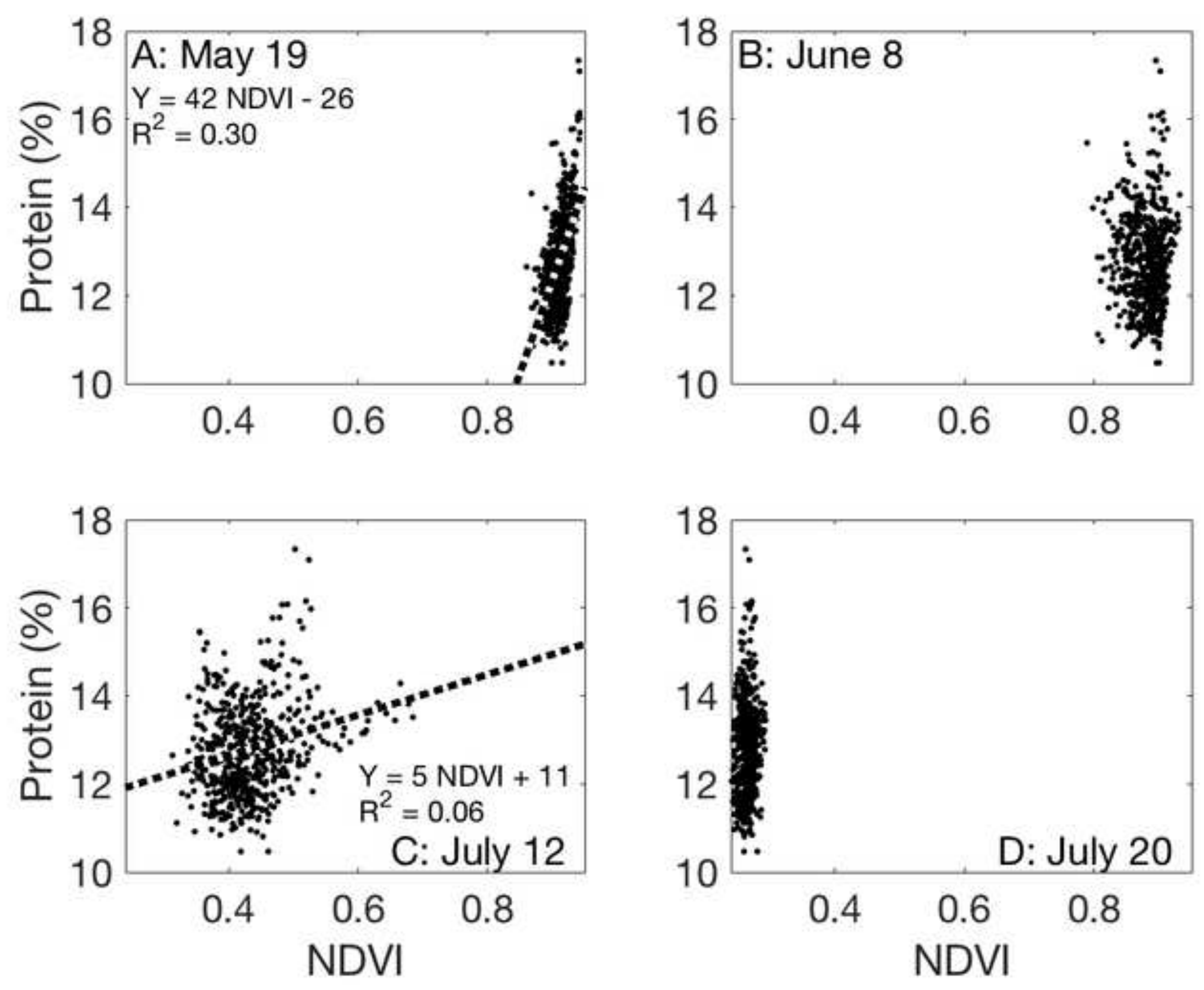


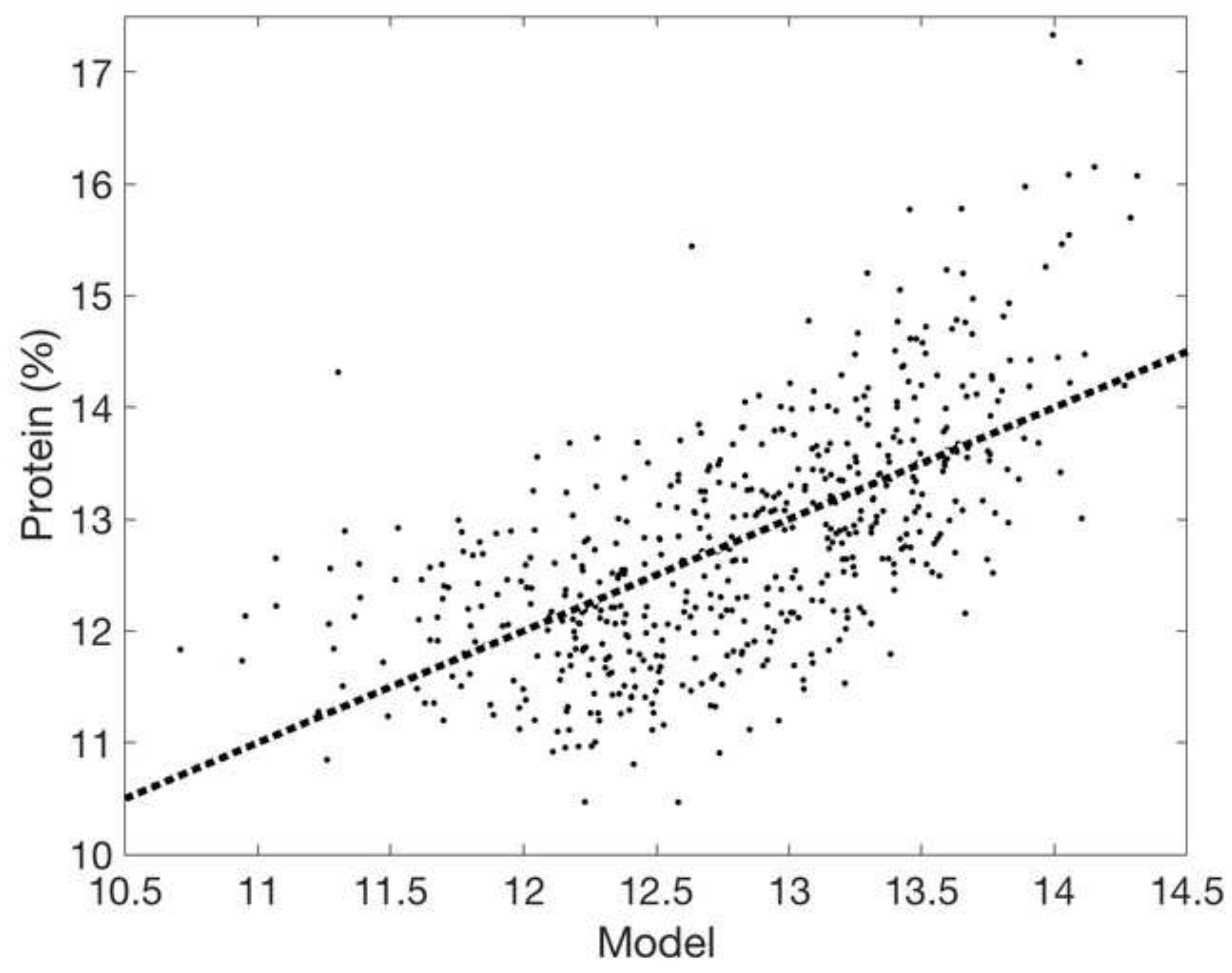



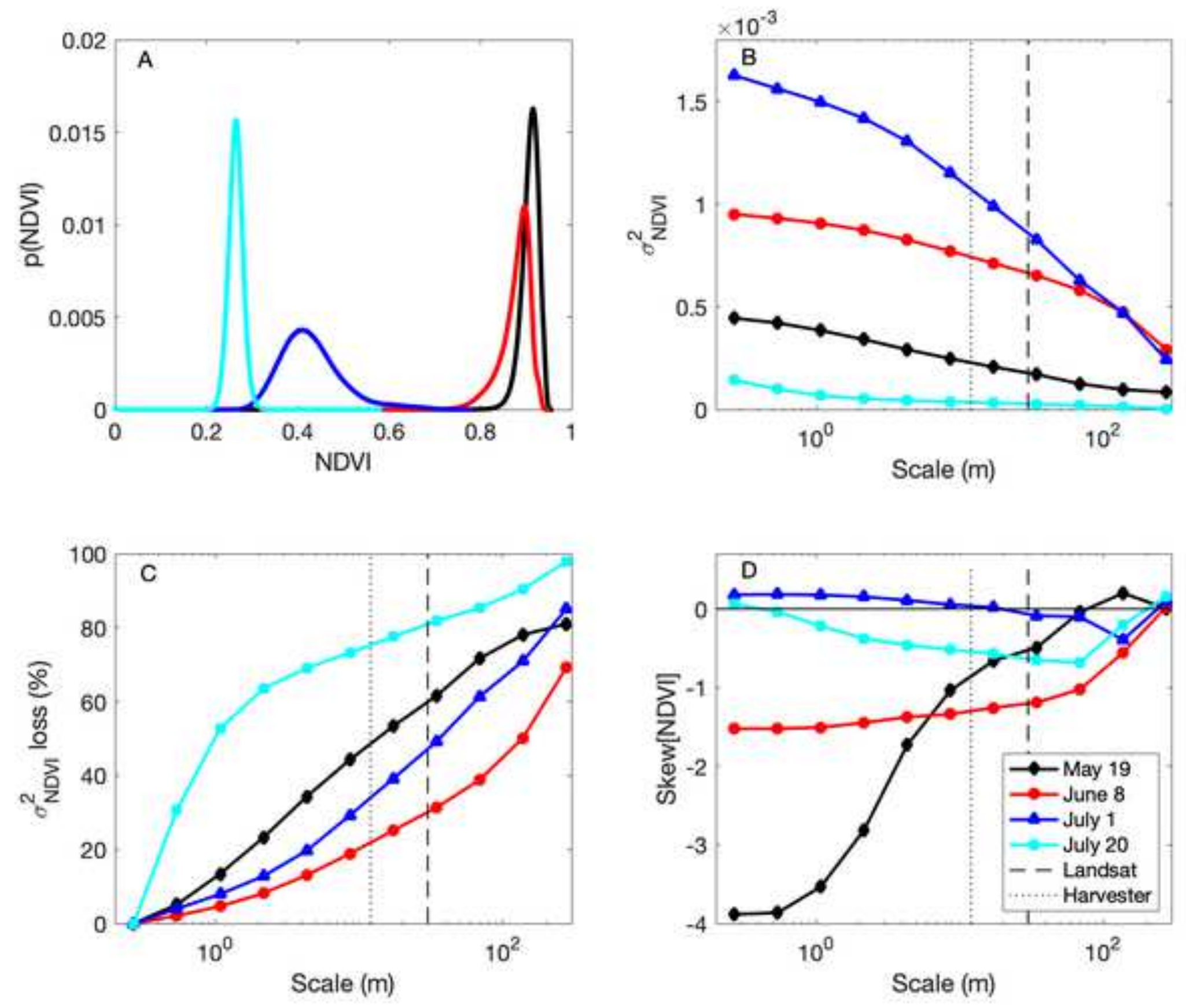

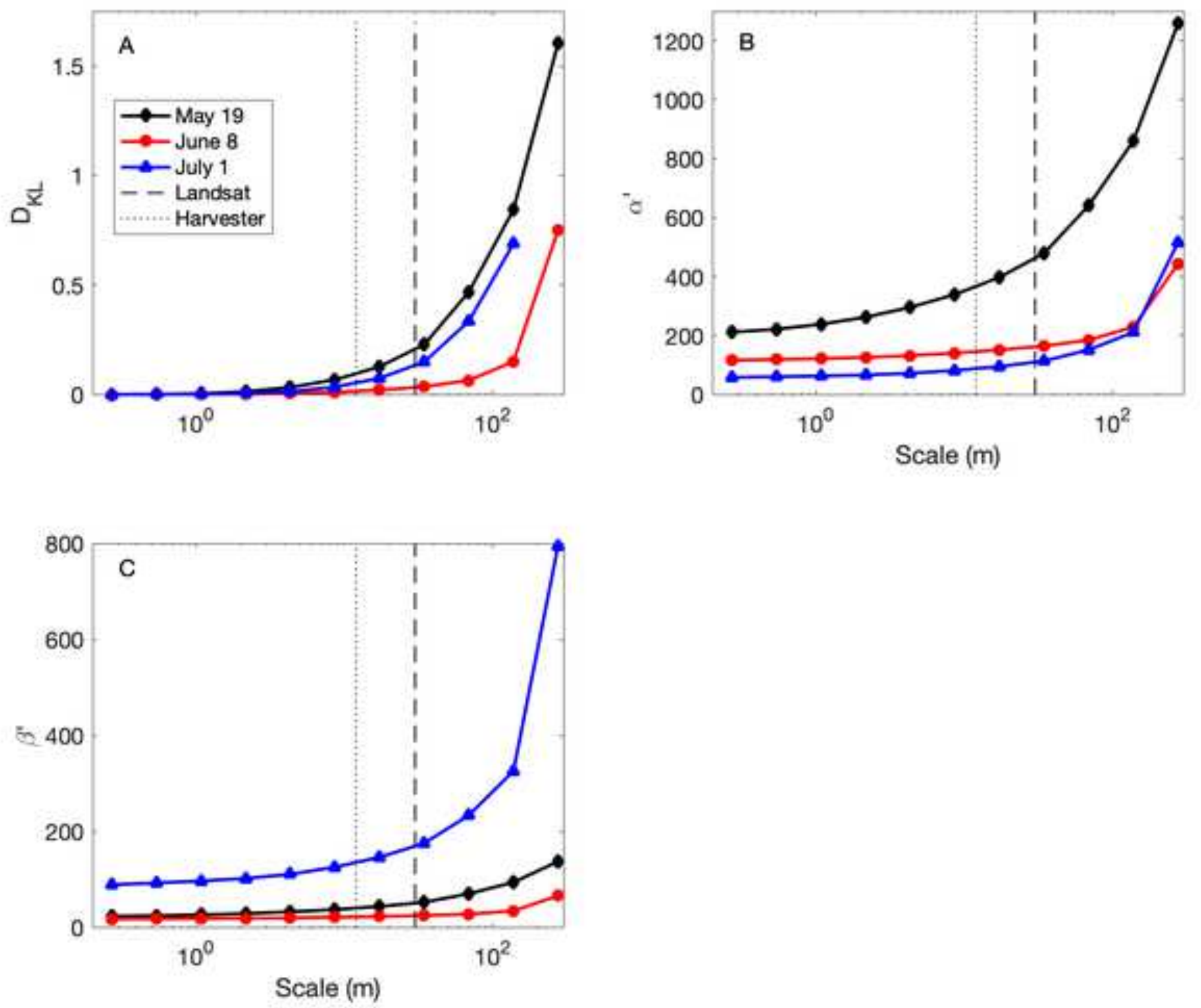


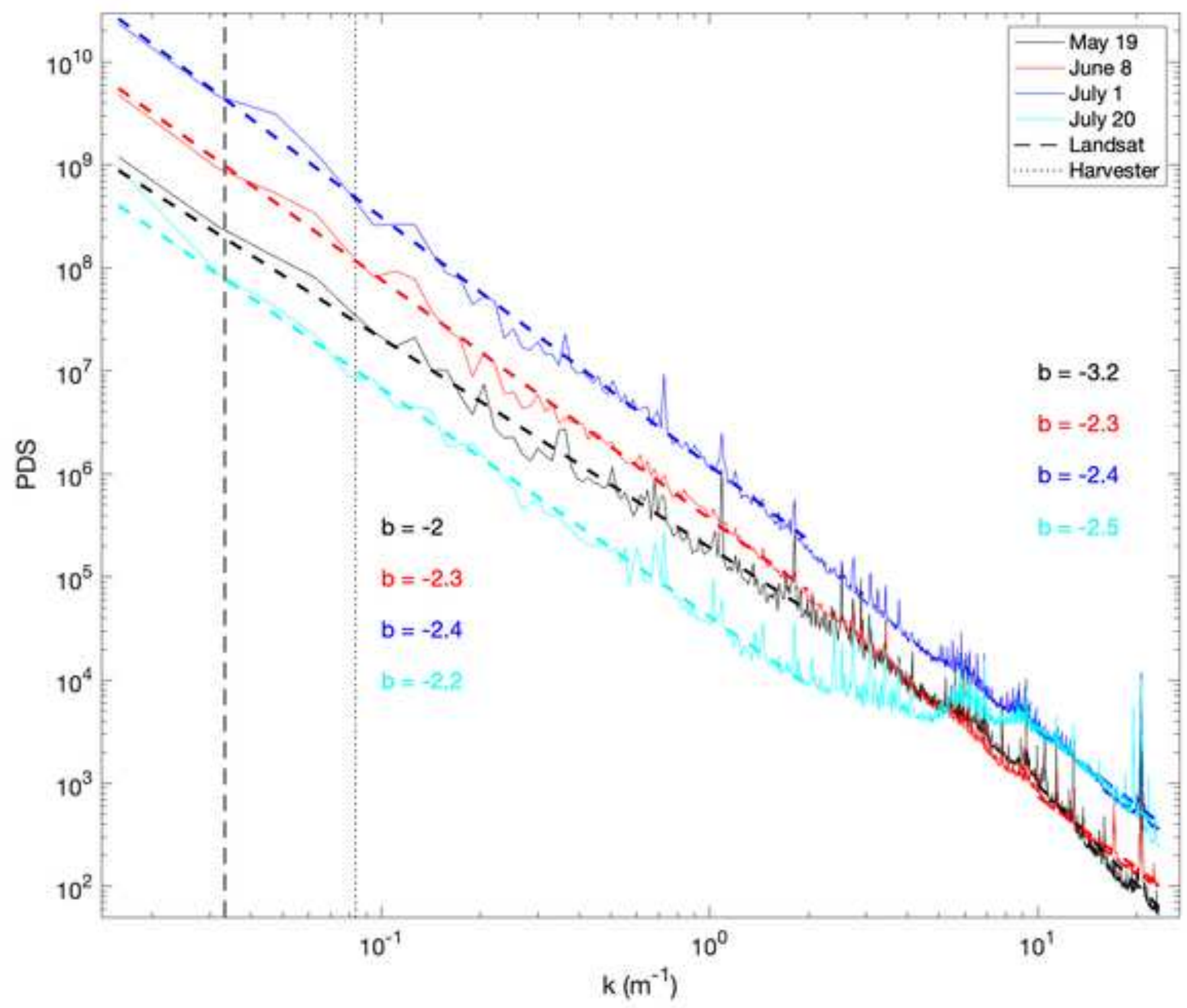




\section{Supplemental Information}

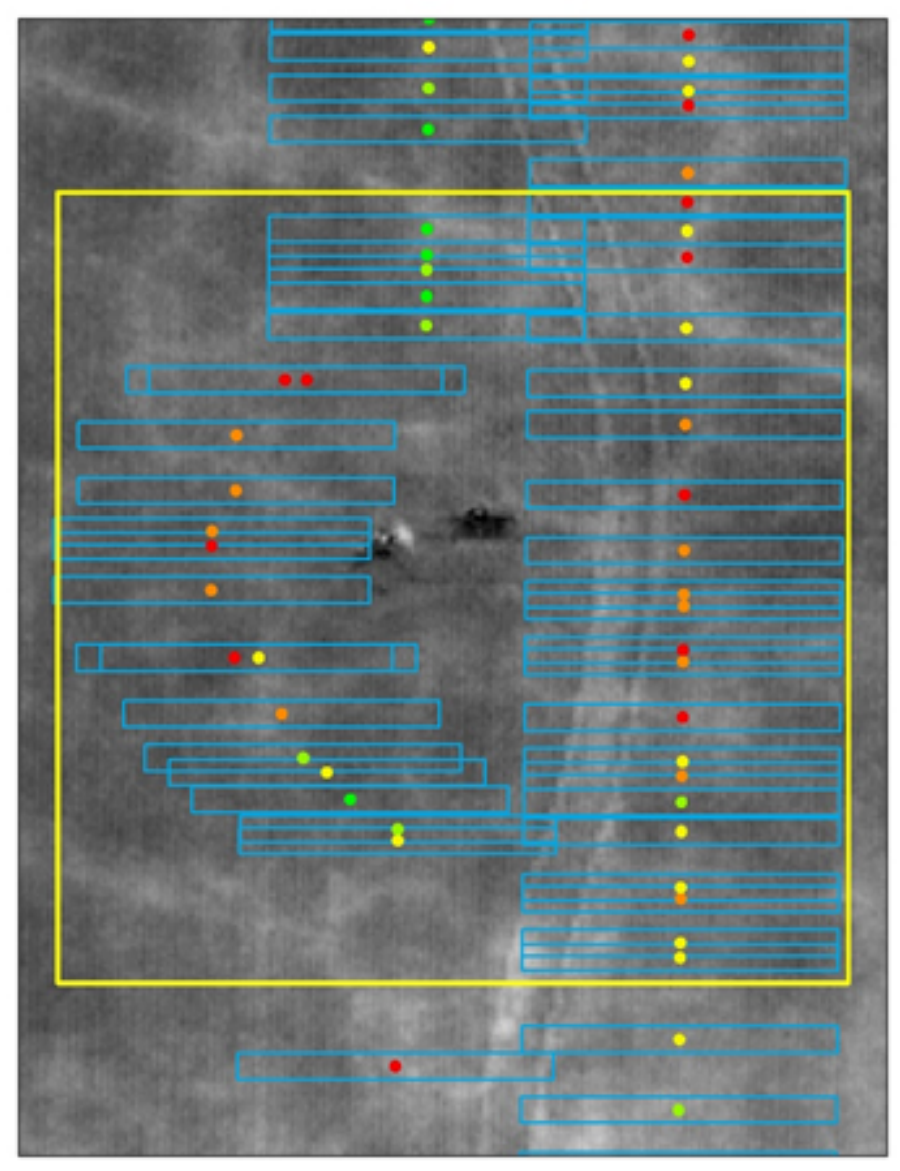

Figure S1. Yield and grain protein content (GPC) data from a combine sensor were averaged across $1 \times 12 \mathrm{~m}$ rectangular buffers to approximate the combine footprint. The dark area in the center of the image is the micrometeorological tower (Fig. 1B), which was avoided by the combine. 